\title{
Direitos humanos e cidadania: a educação como campo de conflito*
}

\author{
Carlos Augusto Abicail \\ Confederação Nacional dos Trabalhadores em Educação
}

\section{0 mundo depois dos ataques aos EUA : trancados no fato ou diante dele?}

Impossível tratar o tema proposto sem fazer, ainda que brevemente, algumas considerações sobre o que alguns observadores chamaram de inauguração do novo milênio. Estamos há menos de trinta dias dos eventos ocorridos nos Estados Unidos, que reacenderam o debate global sobre o parâmetro de convivência humana. Seus desdobramentos na mídia, entretanto, impõem aos educadores uma reflexão irrenunciável sobre a necessária superação de uma visão de educação fundada apenas na informação e na difusão de conhecimento, como se conhecimento e informação não fossem portadores de valores.

Na exploração midiática dos fatos ocorridos há uma justa comoção. O apelo ao sentimentalismo fundamentalista que se sucedeu, entretanto, parece

* Trabalho apresentado no simpósio "Direitos humanos e cidadania", promovido pela CLACSO e realizado durante a $24^{\mathrm{a}}$ Reunião Anual da ANPEd (Caxambu, MG, de 7 a 11 de outubro de 2001). propor soluções dignas de posturas e leituras de mundo do século XXI: faz-se hoje, claramente, a propaganda da guerra.

É notória a tentativa de apagar a memória da motivação do ódio antiamericano e antiocidental, e de eleger a OTAN - Organização do Tratado do Atlântico Norte - ou a ONU - Organização das Nações Unidas - como juízes universais, como se não houvesse nesses organismos tensões e interesses que denotam a desigualdade global a que se chegou, especialmente pelo silêncio nos casos de violações lideradas pelo governo estadunidense. Não será possível considerar aqueles fatos sem aludir a marcas recentes dessas desigualdades: vista grossa ao holocausto ruandês; permissão ao massacre de bósnios; violação da Convenção de Genebra na morte de civis iugoslavos; apoio à violação do direito internacional por Israel; recusa ao Acordo de Kyoto; retirada da Conferência sobre Intolerância; 19 anos do massacre de Sabra e Shatila (Líbano), comandados por Menahen Begin e Ariel Sharon.

Não se pode calar diante da iminência da barbárie insana. Hoje, os riscos mais evidentes dessa tendên- 
cia indicam israelenses desmembrados por psicopatas, palestinos em regime de apartheid, famílias norte-americanas destroçadas; direitos humanos ameaçados.

Ainda que se considere o Taliban responsável pelos injustificáveis ataques de 11 de setembro, efetivamente aquele regime não imaginava tamanho êxito. E as últimas decisões ocidentais de retaliação aos atos terroristas revelam o tamanho do obscurantismo: US $\$ 40$ bilhões para destruir.

Salta aos olhos, porém, a constatação de que vivemos a mudança de protagonismo no projeto global. As ações antiglobalização neoliberal e o Fórum Social Mundial perdem espaço para o recrudescimento belicoso (sob a direção de Bush e Blair) e a propaganda de um fundamentalismo que parece nos colocar sob duas condenações alternativas: o terrorismo abominável e inominado, ou a liberdade infinita do capital.

\section{U $\mathrm{m}$ balanço do século que terminou}

É mais do que oportuno apresentar um balanço sintético do século que terminou.

A distância entre os países ricos e pobres era de: $3 \times 1$ em 1820; $11 x 1$ em 1913; $35 x 1$ em 1950; $44 x$ 1 em 1973; $72 x 1$ em 1992; $77 x 1$ em 2000.

Hoje, se estabelecêssemos um comparativo entre as populações do planeta, aumentariam as razões da indignação e da revolta:

\begin{tabular}{|ll|}
\hline $\begin{array}{l}\text { 20\% DA POPULAÇÃO } \\
\text { GLOBAL MAIS RICA }\end{array}$ & $x$ \\
\hline $86 \%$ do PIB & $1 \%$ do PIB \\
$82 \%$ do mercado & $1 \%$ do mercado \\
$68 \%$ do investimento & $1 \%$ do investimento \\
$74 \%$ das linhas telefônicas & $1,5 \%$ dos telefones disponíveis \\
\hline
\end{tabular}

Em 1998, 200 pessoas mais ricas aumentaram em US $\$ 1$ bilhão os seus ativos, o que corresponde apro- ximadamente à renda de $41 \%$ dos habitantes do planeta; três multinacionais têm renda quase igual a 600 milhões de habitantes dos 43 países mais pobres do mundo; $1 \%$ da renda anual dos 200 mais ricos, o que corresponderia a um valor entre US\$7 e US\$8 milhões, garantiria ensino fundamental para todos.

\section{A educação como campo de conflito nesse contexto}

Toma-se aqui o conceito de educação como processo amplo, presente no trabalho, no movimento popular, no movimento sindical, nos partidos políticos, no sistema escolar. Esse conceito aberto e abrangente permite superar apenas a escolarização como objeto de reflexão e análise, ao mesmo tempo em que estabelece o confronto com desafios e respostas em variados aspectos, como veremos a seguir. Longe de ser uma abordagem que esgota a complexidade dessas relações, apenas serão apontados em forma de tópicos algumas considerações que foram julgadas mais relevantes para inicitar debates.

Para destacar a educação no mundo do trabalho, é indispensável ter claro o significado da supremacia do mercado e seus efeitos mais imediatos e universais.

$1^{\circ}$ A domesticação - tomada no seu sentido de localização geográfica e de subordinação ideológica, essa tendência tem provocado a intensa precarização das relações de trabalho e das capacidades de resistência dos trabalhadores e trabalhadoras, além do deslocamento do local de trabalho para quintais, garagens, salas e dependências dos lares de milhares de famílias em todos os continentes. Nesse sentido, desde as formas mais tradicionais de exploração do trabalho infantil na quebra de coco, nas carvoarias e no sisal, até as mais modernas formas de exploração e de produção on line vêm sendo incrementadas.

$2^{\circ}$ A proximidade/horizontalidade dos proces- 
sos - eliminam-se funções intermediárias e de controle vertical, propondo-se relações mais diretas nas diversas fases de produção e de exploração do trabalho, mesmo no setor de serviços, procurando-se criar a ilusão de maior controle sobre os processos produtivos e de superação de dificuldades processuais. Também a solução de problemas de toda natureza, inclusive do passivo das empresas, passa a ser compartilhada como responsabilidade de todos.

$3^{\circ}$ A ocultação dos conflitos de classe - em ambas as tendências anteriores nota-se uma tentativa insistente de fazer crer que o conflito de classe na relação capital-trabalho já não existe, e que a parceria em todos os momentos é a substituta "natural" das regulações universais, "rígidas e inflexíveis", que não estão adequadas aos novos movimentos que imporiam a colaboração como via de sobrevivência competitiva. Entretanto, não se menciona a eliminação do lucro, da apropriação da mais-valia, da propriedade privada.

$4^{\circ}$ A desvinculação do emprego - a exploração do trabalho e o próprio direito ao trabalho dissociam-se das relações de emprego pela via da informalidade, das restrições de direito, do estabelecimento de trabalho cooperativo, doméstico, voluntário, de aprendizado, “empreendedor".

$5^{\circ}$ As ameaças/reduções de direito - uma tal modernização contém características visivelmente contrárias às conquistas históricas de legislações trabalhistas no direito positivo e apelam fortemente para sua gradativa destruição. $\mathrm{Pa}$ recendo não haver saída para a manutenção do direito ao trabalho e à reprodução da vida, categorias produtivas inteiras desfazem-se e novas gerações de trabalhadores que não conheceram a luta por direitos enveredam pelo encantamento da lenda neoliberal do sucesso em quatro oportunidades:

a) nascer em berço de ouro - bilhões de seres humanos continuam perdendo essa oportunidade;

b) "vir ao mundo com a bunda para a lua" a imensa maioria das parteiras não foram avisadas, ou não havia luar na noite em que nasceram bilhões de seres humanos, ou, ainda, eles nasceram à luz do dia;

c) escolher um "bom partido" - o contrato de casamento civil com gente de "bens", de muitos bens (cartões de crédito internacionais, imóveis rurais e urbanos às dezenas, volumosas contas bancárias e saltitantes aplicações em bolsas de valores);

d) liberdade de iniciativa - cada um vale quanto pode pagar, "quem não tem competência não se estabelece", levar vantagem em tudo, ter esperteza para agarrar as melhores oportunidades, saber aproveitar do bom e do melhor, praticar o tráfico de influência, dar "jeitinho", arrumar um bom "pistolão", se virar...

Os dois primeiros blocos de oportunidades apostam na sorte ou no azar, num fatalismo típico das justificações mais atrasadas. Prevenindo-se das revoltas e possibilidades coletivas de identidade de classe, a proposta liberal (oferecendo o único direito que permite cristalizar - o direito de eleição) salta para os dois outros blocos, sempre individuais e privativos, cujas vantagens são medidas pelos resultados na capacidade de consumir e acumular.

Outro foco de conflito no processo educativo mais amplo está no movimento popular. Um estudo do CLACSO (Conselho Latino-Americano de Ciências Sociais), apresentado por Emílio Tadei, não deixa dúvidas sobre as características mais marcantes e mais motivadoras de esperança para o futuro: 
$1^{0}$ A reação à substituição do senso de direitos pelo de oportunidades - mais do que em qualquer outra época, são as organizações populares - das associações de moradores aos meninos e meninas de rua, dos sindicatos aos movimentos de aposentados, de sem-terra e de sem-teto - que lideram a denúncia desse modelo excludente e redutor e exercem papel fundamental na sustentação da memória histórica da construção dos direitos, de seus custos humanos, culturais e sociais, de suas batalhas políticas ante as novas gerações.

$2^{\circ}$ As manipulações de interesses - por essa mesma razão, as organizações populares são movimentos disputados, pelo seu alto valor convocatório e crédito público, através das reiteradas tentativas de coptação de lideranças, de atrelamento eleitoral e partidário, de institucionalização pela via do acesso ao financiamento estatal e parafiscal ou, na outra extremidade, da criminalização de suas ações.

$3^{\circ}$ A diversidade e a pluralidade de origens, organizações e métodos - as organizações mais genuínas, resistentes, autônomas e duradouras têm múltiplas origens e motivações. Desde vínculos com organizações revolucionárias de esquerda mais tradicionais, passando pela teologia da libertação e importantes organizações religiosas de base, pelo solidarismo espontâneo, até ações de emergência de reação a acidentes, à violência, a catástrofes naturais, de combate às discriminações de distintas matizes, entre outras. Essa pluralidade expressa uma rica experiência que torna mais fácil e ágil o movimento através de lutas comuns em diversos fóruns, sem abandono das identidades e de pautas sociais distintas, ao mesmo tempo em que faz mais complexa qualquer tentativa de controle e atrelamento conservador. $4^{\circ}$ A concorrência do terceiro setor e a ação genuína - fruto dessa diversidade de organizações, muitos laços foram estabelecidos com ONGs (Organizações Não-Governamentais) de defesa de direitos e apoio a lutas populares. Uma verdadeira rede de solidariedade estrutura-se, superando barreiras geográficas e, algumas vezes, ideológicas. Uma nova linha de intervenção de "empresas sociais", porém, está sendo gestada: sobre a declaração de falência do Estado e de impossibilidade do direito, procuram-se edificar como organizações sociais de interesse público, ocupadas em modernizar a "caridade", com ações focais e forte propaganda institucional.

Mas há de se considerar ainda o movimento sindical como agente educativo e como campo de conflito. Pontualmente, sua intervenção histórica recente expressa-se em variadas formas e direções:

$1^{\circ}$ Construção e ampliação de direitos e defesa o final do século passado foi denso de mobilizações e de construção do mais fundamental instrumento de luta da classe trabalhadora: os sindicatos. Partícipe da luta contra a carestia, a ditadura e o controle estatal de suas estruturas, forjou-se, no Brasil, a CUT - Central Única dos Trabalhadores -, a mais duradoura e expressiva central sindical da América Latina, fundada na democracia interna, na liberdade e autonomia de organização e na efetiva participação nas lutas gerais por direitos civis e políticos. É tão forte sua presença, que é impossível pensar qualquer grande mobilização no Brasil sem a sua participação. A abrangência nacional e a representação forte na cidade e no campo inauguram uma identidade clara dessa central sindical, com seus princípios, sua estruturação representativa, suas atuações institucionais e de massa. Embora inexistente na lei, firma-se pela sua representatividade efetiva. Seus primeiros dez 
anos foram nitidamente voltados para a construção e ampliação dos direitos dos trabalhadores. A ferocidade da globalização neoliberal, contudo, cada vez mais cerca e viola direitos, colocando em pauta, de maneira mais evidente, a defesa das mínimas garantias duramente alcançadas na forma das leis ou da Constituição, nos últimos dez anos.

$2^{\circ}$ Autonomia e liberdade/cooptação - do mesmo modo que no movimento popular, as estruturas sindicais são disputadas ideologicamente pelo seu crédito público e pela sua capilaridade. No outro pólo da autonomia e da liberdade de organização encontram-se os interesses de grupos "pelegos", adeptos da flexibilização absoluta, amigos dos detentores dos cofres públicos e nítidos defensores da colaboração de classe. Assim, o movimento sindical é campo de disputa constante. A própria participação nas atividades de mobilização, nos processos de eleição sindical, nas assembléias e nas greves coloca às claras as diversas leituras estratégicas e táticas de luta ou de subordinação. No Brasil, a Força Sindical e a Social Democracia Sindical são expressões inequívocas do pólo vertente à cooptação.

$3^{\circ}$ Desemprego estrutural - esse é o mais poderoso fator de debilidade para o movimento sindical. Por um lado, assusta e debilita. Por outro, forja novas formas de organização por local de trabalho, novas estratégias de luta e novos campos de atuação sindical, seja na formulação de alternativas, na denúncia das manobras empresariais (geralmente em conluio com ações governamentais) ou na proposta de um projeto de desenvolvimento soberano, sustentável e solidário. As modalidades de representação de desempregados, autônomos, aposentados e terceirizados vêm provocando novos desenhos estruturais e novas pautas, levando aos sindicatos demandas por formação profissional e requalificação, formas de organização do trabalho e de produção co-gestionária inusitadas.

$4^{\text {o }}$ Políticas compensatórias/serviços de apoio por um lado, há fortes apelos para a afirmação dos sindicatos em políticas compensatórias estabelecidas por acordo ou oferecidas diretamente, com serviços de apoio jurídico, psicológico, educativo, assistencial, reparatório, de cultura, de lazer, de desporto, de informação e de formação. Por outro, o próprio agente estatal, pela via da desassistência pública direta, oferta acesso a programas viabilizados por recursos fiscais e parafiscais, desde que administrados e/ou consorciados por organismos privados.

$5^{\circ}$ A ressignificação de finalidades e objetivos diante de tais pressões, as organizações sindicais autônomas vêem-se compelidas e convocadas a disputar a ressignificação desses fenômenos, orientando projetos e programas, investindo na articulação entre mobilização de massa e ação institucional, formação de quadros dirigentes e formação básica. Enfrenta, assim, o dilema entre a sustentação de sua autonomia e liberdade e a disputa pelo controle de fundos públicos destinados ao apoio e à reparação de perdas do trabalhador.

$6^{\circ}$ A atração da juventude - trata-se de um dos mais agudos desafios dos sindicatos ante a sociedade do desemprego e da proclamação enganadora do fim da história. A atração da juventude passa pela estratégia ante os novos postos de trabalho qualificado quase na mesma intensidade que nas formas mais primárias de exploração do trabalho com baixa qualificação. Essa diversidade de linguagens e de expectativas tem revelado uma grande necessidade de recuperação da memória histórica, da reafirmação de um pacto intergeracional 
na promoção da vida e na absorção de práticas menos ortodoxas de organização e de expressão das potencialidades presentes. Além disso, a sensação do eterno recomeçar é uma tentação cuja recusa deve ser cotidiana.

$7^{\circ}$ A flexibilização barbarizadora - não é novidade que se multiplicam os empregos temporários, terceirizados, precários, informais, domésticos, autônomos, "por conta" (de quem?). Um velho e novo universo do mundo do trabalho, que a tradicional representação sindical não é suficiente para alcançar. Muitas vezes, a única forma de se obter renda oriunda do trabalho situa-se no limite da marginalidade e da violação. Dessa forma, a criatividade e a solidariedade abriram brechas na intervenção sindical e geraram estruturas paralelas ou autônomas que lutam por extensão de direitos, por acesso a crédito, por regulação de contratos e serviços etc.

$8^{\circ}$ As outras formas de organização da produção e de geração/distribuição da renda - é nesse outro mundo do trabalho, de resistência e de sobrevivência, que surgem genuínas experiências de economia solidária, de cooperativas de produção e de consumo, de cooperativas de serviços, dos lixões aos transportes alternativos, das empresas de autogestão às experiências de verticalização da agricultura familiar, nas periferias dos grandes centros e nos assentamentos. A memória e a ação direta e solidária dos sindicatos têm sido fundamentais para a sustentação material, política e cultural dessas experiências ricas que reclamam outro projeto para o Brasil.

A educação nos partidos políticos enfrenta também focos de tensões. Alguns desses pólos conflituosos são listados neste artigo:

$1^{\circ}$ Ideologia e programa/pragmatismo eleitoral - o grande choque dos avanços de representação democrática ante a integração global subalterna desafia a construção partidária a uma firmeza programática, ainda que sistematicamente ameaçada pelo cálculo eleitoral. Nesse particular, a permanente afirmação dos princípios ideológicos e programáticos dos partidos democrático-populares tem sido o principal eixo de tensão nos calendários eleitorais e nos processos educativos que eles encerram.

$2^{\circ}$ Coronelismo político/radicalidade democrática - a ruptura com o coronelismo fisiológico tem sido a luta prioritária na ocupação dos espaços de representação institucional alcançados pelos partidos democrático-populares. Criando espaços e tempos de participação popular direta em conselhos, no orçamento participativo, em conferências municipais e seminários temáticos de políticas públicas, essas experiências encerram fortes momentos de radicalidade democrática, nem sempre formais, porém muito expressivos de seu conteúdo emancipador.

$3^{\circ}$ Programa/opinião pública - modernamente, esse é outro foco de tensão. Boa parte das políticas de governo é pautada em pesquisas de opinião. Pior: muitas vezes o programa é falsificado pela propaganda, para ganhar a opinião pública. Os meios de comunicação e a formação da opinião pública acerca de determinadas medidas e programas são componentes fortíssimos das decisões e do restrito campo de democratização do acesso à informação e à participação no processo decisório. Vale observar o volume de recursos utilizados em propaganda governamental e institucional, e a desproporcionalidade de tempos e de espaços de exposição e de debate entre as políticas oficiais e as propostas alternativas.

$4^{\circ}$ Organização - a radicalidade democrática nas 
estruturas de poder estatal força a alteração das estruturas partidárias, questionando o centralismo democrático, a verticalização excessiva, a federação de mandatos e a ausência do debate político. Processos mais representativos de eleição da direção, de decisão política e de definição de estratégias e táticas de campanha de alianças eleitorais e de programas ampliam os horizontes de prática pedagógica dos partidos voltados para a mobilização popular e para a construção do socialismo, superando jargões pesados e a forte carga de rejeição patrocinada pelas forças de direita.

$5^{\circ}$ Mobilização - um partido de massas necessariamente estará vinculado aos movimentos sociais e na dianteira das principais mobilizações que colocam em xeque um projeto de sociedade, um código de valores, um status quo legitimado. A experiência educativa de partidos populares é claramente manifestada nas ações de mobilização popular, desde o bairro até as grandes ações de repercussão nacional e internacional.

$6^{\circ}$ Relação institucional/movimentos - à medida que crescem os espaços de poder e de representação desses partidos populares e das lideranças vinculadas ao movimento social, cresce também a tensão entre os movimentos e a ação institucional, especialmente ante as demandas reprimidas por longo período de tempo e às limitações da ação estatal. Particularmente na condução do poder executivo, tem sido muito freqüente um descompasso no tempo e no método de decisão e implementação de medidas reclamadas pelos movimentos e não implementadas pelo Estado. Este é um campo de aprendizagem e de criação em franca expansão.

$7^{\circ}$ Corrupção/descrédito público - impossível deixar de mencionar que dentro das ações educativas está o combate à corrupção e o resgate do crédito público para a necessidade de organização e de representação partidária. Entre as grandes lições que credenciam e legitimam vivamente os partidos de esquerda, sem qualquer dúvida, situa-se sua batalha contra a corrupção, suas práticas de depuração interna e a possibilidade de resgate do crédito público.

Por último, são listadas breves considerações sobre o conflito educativo no sistema escolar:

$1^{\circ}$ Há uma crise de finalidade e objetivos - a escolarização ainda é feita com o objetivo formal de se atingir um bom emprego ou de acrescentar renda. Indicadores de ocupação recentes, no entanto, desmentem a clássica relação direta entre crescimento de oferta de emprego e maior escolarização, ou de crescimento de renda diretamente vinculado à maior escolaridade. Há, outrossim, um rebaixamento generalizado no rendimento dos salários e aumento progressivo de participação nas taxas de desemprego de pessoal de nível técnico e superior, além do fato de ocupações tradicionalmente desqualificadas serem disputadas por portadores de diplomas. A construção da educação como um direito universal é fortemente impactada pelo discurso ainda voltado para uma educação utilitária para o mercado de trabalho, ou para a exploração das chamadas vantagens comparativas no universo da divisão internacional do trabalho.

$2^{\circ}$ Mudanças na organização - nos sistemas, no currículo, no financiamento, na gestão - a redução do Estado brasileiro se faz sentir num amplo programa de reformas educacionais conservadoras que atuam fortemente no núcleo da oferta educacional. É nítida a retração do papel da União como garantidora da oferta 
educacional em todos os níveis, assim como a tendência acelerada de municipalização da educação infantil e fundamental, e restrição dos estados ao ensino médio. Os limites dessa divisão de competências enfrentam explosiva demanda comprimida há anos, sem suporte financeiro do poder público para assegurar universalidade com qualidade. Multiplicam-se formas de gestão privatizada de recursos públicos, através de manobras como a criação de "unidades executoras privadas" em substituição aos conselhos escolares e às mais variadas formas de parcerias, assim como a inserção do trabalho voluntário. A visão utilitária da educação para atender ao mercado de trabalho faz recrudescer a orientação das escolas para o desenvolvimento das habilidades e competências requeridas pelo mercado - sempre seletivo e excludente -, numa estratificação da oferta de acordo com a chamada clientela escolar. A essa tendência corresponde a afirmação das oportunidades educacionais em substituição ao direito à educação. As taxas de matrícula e de promoção substituem o valor da aprendizagem. A avaliação escapa do controle interno dos projetos pedagógicos e salta cada vez mais intensivamente ao poder central do MEC Ministério da Educação e do Desporto.

$3^{\circ}$ A pluralidade de concepções pedagógicas há, entretanto, brechas legislativas oriundas do forte movimento de educadores do final do século XX, fundado nas lutas por democracia e autonomia do processo educativo perante os governos. Dessa forma, a pluralidade de concepções pedagógicas tem sido campo fértil para a promoção de experiências emancipadoras, notadamente em escolas públicas e em redes inteiras administradas por governos populares em alguns estados e municípios. Esse tensionamento efetivo tem possibilitado a disputa de projetos emancipatórios e abrangentes que vinculam a educação à cida- dania, à radicalidade democrática, à exigência do direito.

$4^{\circ}$ A Constituição de 1988 assegura, contudo, a "coexistência" do público com o privado. E, especialmente na educação infantil e no ensino superior, a expansão ocorre por meio da iniciativa privada, muitas vezes sem o controle do poder público. Essa herança da história da educação brasileira coloca, mais do que em qualquer tempo, a exigência do controle público da oferta de qualidade e a necessidade de criação e fortalecimento de órgãos normativos e fiscalizadores do sistema, com forte capacidade de controle social.

$5^{\circ} \mathrm{O}$ confronto entre prática social/prática pedagógica - cada vez mais a coerência entre os valores humanos e políticos confronta-se com a prática pedagógica. Há um forte investimento oficial na difusão de métodos e técnicas de ensino que atendam aos chamados "parâmetros curriculares nacionais" e a um modismo na organização curricular por ciclos de promoção automática, que não se adaptam à prática social dos profissionais e dos governos. Essa incoerência manifesta tem causado grande insatisfação de educadores e da comunidade escolar, frustrando, muitas vezes, as matrizes de experiências promissoras, desde que fundadas em políticas públicas de suporte social promotoras de inclusão e garantidoras de direitos mais abrangentes.

$6^{\circ}$ Uma escola de conhecimento/informação - os arautos da modernidade neoliberal desejam que a educação escolar seja apenas a facilitadora de acessos e a difusora de informações. Assim, o processo escolar esvazia-se da capacidade de criar e desenvolver conhecimento, de gerar atitudes que valorizem a criatividade, a curiosidade, a inventividade, as artes e as manifestações multiculturais. É meramen- 
te instrumental para ensinar a abrir janelas por onde toda a informação pode ser acessada, já processada, filtrada e subordinada aos interesses de seus promotores e financiadores. Esse choque opõe uma prática voltada para o conhecimento a uma técnica restrita ao consumo de informações.

$7^{\circ}$ Por essa razão, o cerne do conflito está em promover e defender a conservação e a emancipação. Esse é um divisor de águas fundamental na definição do papel da educação escolar e na implementação das chamadas reformas de ensino. Hoje, a aspiração do movimento de educadores por reformas vê-se confrontada com a decisão de medidas de caráter majoritariamente conservador.

$8^{\circ}$ Os impactos na formação/contratação/carreira - os avanços notórios no serviço público de educação nessas áreas são fortemente ameaçados pela reforma administrativa, pelo avanço de processos de contratação precária e temporária, pela municipalização e pela terceirização de serviços. À demanda por melhores salários soma-se a demanda por qualificação crescente, por defesa de garantias estatutárias e legais freqüentemente violadas por governos, e a luta pela manutenção de direitos de carreira. Ao processo de desprofissionalização corresponde uma luta dos sindicatos de educadores pelo restabelecimento do estado de direito em muitos casos. A maioria das greves dos últimos anos reclama direitos formais já assegurados: reajuste salarial anual, salários atrasados, pagamento de férias e do décimo terceiro salário, realização das promoções previstas na carreira, extensão de benefícios à aposentadoria, entre outros.

$9^{\circ}$ Há novas identidades profissionais - o sistema escolar no Brasil vem assumindo tarefas complementares no âmbito da saúde, da nu- trição, da renda. São inúmeros os programas ditos sociais vinculados à matrícula. Em diversos casos, porém, a escola é o único equipamento público existente no bairro, assumindo a condição de referência para a presença do poder público. Ademais, o cotidiano escolar impõe a construção de um ambiente educativo em que as inter-relações funcionais assumem verdadeiramente uma característica pedagógica que vem sendo levantada, como a reclamação por novas profissões de educadores: em multimeios didáticos, na nutrição escolar, na manutenção da infra-estrutura e nos serviços de administração.

$10^{\circ}$ A escassez do tempo/espaço, como fruto dessa hipertrofia funcional, da própria expansão da demanda, das más condições de trabalho, dos baixos salários e do múltiplo emprego, os trabalhadores da educação são sujeitos ao agravamento do impacto da carga de trabalho; da tensão entre afeto e razão; do abismo entre desejo, capacidades que já possuem e condições concretas de realizá-lo. Fato é que metade dos profissionais já sofrem de algum sintoma de desistência ("síndrome de burnout"), em boa parte produto de três consciências presentes na categoria: sabe que se pode fazer melhor; sabe o que é necessário para alcançar isto; e a autoridade competente não escuta e não resolve os problemas estruturais e organizacionais reclamados.

$11^{\circ}$ A oposição entre a autonomia proposta e reivindicada e a forte concentração do controle e da formulação/descentralização da execução - esse, provavelmente, é um dos principais eixos das reformas conservadoras que localizam a responsabilidade pela execução e centralizam a formulação e a avaliação. Não há prova mais consistente desse processo do que a observação da natureza dos programas e projetos oficiais centrados no Ministério da 
Educação e oferecidos aos sistemas estaduais e municipais como condição para acesso às verbas federais. Assim, há também o aprofundamento dos processos de avaliação centralizada representados pelo SAEB (Sistema de Avaliação da Educação Básica), pelo ENEM (Exame Nacional do Ensino Médio) e pelo "provão" (Exame Nacional dos Cursos Superiores) e a forte preocupação pela classificação dos resultados e pela formação de uma opinião pública limitada aos critérios da produtividade e da seletividade dos cursos, dos estabelecimentos e instituições, e dos profissionais.

Pelo exposto, ouso apresentar, sinteticamente, uma caracterização geral da educação como um movimento:

a) que reage ao neoliberalismo;

b) que sofre e denuncia a violação à liberdade e à autonomia;

c) que não claudica perante a criminalização judicial das iniciativas e representações;

d) que enfrenta as estratégias de novas segmentações e a desarticulação;

e) que repudia a promoção da violência, a precariedade da infra-estrutura e das relações de trabalho, e a desistência;

f) que não se resigna ante os três eixos de tensão: a dependência de terceiros para a formulação de propostas, a pluralidade de fontes de conhecimento e informação, a ausência de identidade e de protagonismo político; g) em que a aliança social é capaz de enfrentar os aparentes conflitos de direitos e conquistas históricas demandados socialmente (MST Movimento dos Trabalhadores Rurais Sem Terra -, CONTAG/CUT - Confederação Nacional da Agricultura/Central Única dos Trabalhadores -, APMs - Associações de Pais e Mestres -, ONGs - Organizações Não-Governamentais - etc.).

Não resta muito senão superar "A ética míope do fundamentalismo", como nos diz Frei Betto (Agência Adital, São Paulo, 11/10/2001):

As ideologias foram supostamente derrubadas com a queda do muro de Berlim.

Agora, com a queda das torres do WTC, emergiram as teologias... nunca se recorria tanto à linguagem religiosa para justificar, de um lado, o terrorismo de face oculta; de outro, o de rosto estatal.

É como se a racionalidade moderna naufragasse, de repente, em sua própria incapacidade de encarnar-se em atos humanos.

Pensamos o que não ousamos fazer, fazemos o que podemos justificar, queremos o que não convém à razão ética...

Quem fala em democracia instaura a ditadura, quem promete assegurar a paz faz a guerra, quem professa o nome de Deus não O reconhece na face do semelhante; quem aspira por um mundo melhor não ousa admitir a transformação da realidade atual.

Importam o vigor político e a militância acadêmica. Invoco, aqui, um dos versos do hino de fundação da Central Única dos Trabalhadores: "Organizar a esperança, acender a rebeldia". 
A place of production and the production of a place: the history and historiography presented in the Working Group History of Education da ANPEd (1985-2000)

This text analyses the ground covered by the ANPEd Working Group on the History of Education (1985-2000) reconsidering the characteristics of the productions presented in the group and its constitutive process as a "place of production" for Brazilian historical educational research. It emphasises the role of the Working Group as a place for theoreticalmethodological discussions and for the nurturing of new research perspectives. It also identifies the emergence of theoretical perspectives and methodological options that have marked national production in this area.

Key-words: history of education, ANPEd working group on the history of education, educational history and historiography, Brazilian historicaleducational production, history of Brazilian education.

Maria Teresa Esteban

A avaliação no processo ensino/ aprendizagem: os desafios postos pelas múltiplas faces do cotidiano Apresenta uma reflexão sobre o cotidiano de uma escola comum, tomando com especial atenção a avaliação, prática tradicionalmente imersa na previsibilidade, na repetição e no saber, mas que também guarda em si o oposto. Traz para discussão o processo cotidiano de avaliação de uma turma considerada com dificuldades de aprendizagem, em que era difícil classificar as crianças segundo padrões previamente estabelecidos, dar notas, até mesmo distinguir o certo do errado. Uma questão tornou-se central para as professoras: como atuar em uma escola que assume a heterogeneidade como um dos pilares da prática pedagógica? A busca desta resposta mobiliza a escola no sentido de redefinir sua prática, com destaque para a avaliação. Movidas pelo fim de suas certezas, as professoras constroem caminhos para superar o desafio assumido.

Palavras-chave: avaliação, ensino/ aprendizagem, cotidiano.

Evaluation in the teaching-learning process: the challenges posited by the multiple facets of daily life

The article presents a reflection on the daily routine of an ordinary school, giving special attention to evaluation, a practice which is traditionally immersed in predictability, repetition and knowledge, but which also contains within itself the opposing possibilities. It raises for discussion the daily process of evaluation of a class with supposed learning difficulties, in which it was difficult to classify the children in accordance with previously established standards, the attribution of marks, and even how to distinguish right from wrong. For the teachers one question was central: how to teach in a school which accepts heterogeneity as one of the pillars of pedagogical practice? The search for a reply mobilised the school in the sense of redefining its practice with emphasis on evaluation. Motivated by an end to their certainties the teachers constructed ways of facing up to the challenge.

Key-words: evaluation, teaching/ learning, daily life.

Carlos Augusto Abicail

Direitos humanos e cidadania: a educação como campo de conflito Aborda a educação a partir do que alguns observadores chamaram de inauguração do novo milênio, diante dos eventos ocorridos nos Estados Unidos, que reacenderam o debate global sobre os parâmetros de convivência humana. Seus desdobramentos, especialmente na mídia, impõem aos educadores uma reflexão irrenunciável sobre a necessária superação de uma visão de educação fundada apenas na informação e na difusão de conhecimento, como se conhecimento e informação não fossem portadores de valores. Assume um conceito de educação como processo amplo, presente no trabalho, no movimento popular, no movimento sindical, nos partidos políticos, no sistema escolar. Este conceito abrangente coloca nossa reflexão para além da escolarização e confronta-nos com desafios e respostas em variados aspectos.

Palavras-chave: educação, direitos humanos, cidadania.

\section{Human rights and citizenship:} education as a field of conflict

The text broaches education from the viewpoint of what some observers have called the inauguration of the new millennium, marked by those events which took place in the United States and, consequently, rekindled the global debate concerning the parameters of human conviviality. Its developments, especially in the media, demand that educators reflect urgently on the need to surpass a vision of education based only on information and on the diffusion of knowledge, as though knowledge and information were not imbued with values. It conceives education as an ample process which is present in work, in the popular and trade union movements, in political parties and in the school system. The broad concept situates our reflection beyond that of mere schooling and confronts us with challenges and replies in various aspects.

Key-words: education, human rights, citizenship. 